\title{
O Teatro Temporário ao Ar Livre na Unirio: um site-specific na Quadrienal de Praga de Desenho da Performance e Espaço em 2019
}

\author{
Evelyn Furquim Werneck Lima \\ Universidade Federal do Estado do Rio de Janeiro - UNIRIO, Rio de Janeiro/RJ, Brasil \\ E-mail: evelyn.lima@unirio.br
}

Resumo

Partindo das orientações dos curadores da Quadrienal de Praga de Desenho da Performance e Espaço de 2019, os arquitetos, cenógrafos e figurinistas que integram o Laboratório de Estudos do Espaço Teatral e Memória Urbana existente desde 1994, selecionaram entre outras experiências, a proposta site-specific, um espaço efêmero inicialmente concebido para uma única performance exibida em dezembro de 2016, em homenagem aos 400 anos da morte de Shakespeare, quando a equipe projetou o Temporary Open-Air Theatre e encenou fragmentos da peça A Tempestade na Universidade Federal do Estado do Rio de Janeiro. Naquela ocasião foi gravado um vídeo com 40 minutos do processo colaborativo da concepção arquitetônica e do espetáculo, que serviu de base para a elaboração de um novo vídeo e decupagem do espetáculo para o minidocumentário de 5 minutos - detalhando a arquitetura do site-specific - que foi enviado aos curadores da $P Q 19$, tendo sido selecionado entre os finalistas. O vídeo do projeto do Teatro Temporário ao Ar Livre ficou em exibição durante o período de 06 a 16 de junho na Prague Quadrennial 2019 e este artigo discute o processo de criação com base nos conceitos de Pearson e Shanks (2001) e Irwin (2007).
Based on the curators' guidelines of the Prague Quadrennial of Performance and Space Design 2019, the architects, scenographers and costume designers who research at the Laboratory for Theatrical Space and Urban Memory Studies (existing since 1994), selected, among other experiences, the site-specific proposal, an ephemeral space initially designed for a single performance staged in December 2016, in honor of 400 years since Shakespeare's death, when the team designed the Temporary Open-Air Theatre and staged fragments of The Tempest at the Federal University of the State of Rio de Janeiro. At that time, a 40-minute video of the collaborative process of the architectural design and the show was recorded, which served as the basis for the preparation of a new video and decoupage of the show for the 5-minute mini-documentary - detailing the site-specific architecture - which was sent to the curators of PQ19, having been selected among the finalists. The video of the Temporary Open-Air Theatre project was shown during the period from June 6th to 16th at Prague Quadrennial 2019 and this article discusses the creation process based on the concepts of Pearson and Shanks (2001) and Irwin (2007).

\footnotetext{
Ephemeral Architecture. Site-Specific.
}

Temporary Theatre. 
A Quadrienal de Praga de Desenho da Performance e Espaço, anteriormente designada como Quadrienal Internacional de Cenografia e Arquitetura Teatral teve sua primeira edição em 1967 visando valorizar os trabalhos cenográficos e as arquiteturas destinadas às artes performáticas por meio das exposições quadrienais, festivais e programas educacionais de obras de profissionais da arte do teatro, em especial designers, artistas e arquitetos, ao mesmo tempo em que inspira e educa o público em geral, incentivando a experimentação, a criação de redes e a inovação no campo das artes cênicas. Lembrando da mudança de nome e de conceituação ocorrida em 2011, o cenógrafo e historiador Christopher Baugh reitera que a Quadrienal de Praga enfatizando o potencial dramatúrgico da cenografia e das transformações do conceito de arquitetura para o teatro -, é o mais importante evento que reúne arquitetos e cenógrafos, discutindo suas práticas exercidas em todos os países do mundo (BAUGH, 2013, p. 226). Em 2015, a Quadrienal de Praga recebeu o EFFE Awards, distinguida como um dos festivais europeus mais significativos da Europa.

Na edição de 2019, com curadoria inicial do premiado arquiteto Andrew Todd, o formato da exposição de arquitetura teatral buscou ser o mais democrático possível, com a chamada aberta feita diretamente a artistas e organizações. Os projetos destinados às artes cênicas, grandes e pequenos, poderiam ter sido criados nos últimos 6 anos, incluindo desde espaços efêmeros em locais remotos para um único evento até centros multimilionários de artes cênicas. Para Todd, "as performances contemporâneas acontecem em muitos espaços fora dos teatros tradicionais e podem ser tão empolgantes e válidas quanto aquelas que ocorrem em edifícios tradicionais destinados às artes performáticas e projetadas exclusivamente por empresas de arquitetura" (TODD, 2018. Documento eletrônico)'.

1 "[...] contemporary performances take place in many spaces outside of traditional theatres, and these can be just as exciting and valid as those in traditional multifunctional performing arts structures made exclusively by architectural firms" (TODD, 2018. Documento eletrônico).
Cabe ressaltar que o júri internacional formado por Dorita Hannah, Andrew Filmer e Monica Raya realizou também excelente trabaIho de avaliação das obras apresentadas por meio de vídeos de 5 minutos, tendo selecionado os três melhores trabalhos entre os finalistas.

Uma das seções mais concorridas da Quadrienal de Praga de Desenho da Cena e Espaço de 2019 foi a Exposição de Espaços para a Performance intitulada Our Theatre of the World Performance Space Architecture Exhibition. A primeira chamada publicada já despertou a atenção dos arquitetos e cenógrafos do Laboratório de Estudos do Espaço Teatral e Memória Urbana-LEG T5 que decidiram concorrer, apresentando um projeto executado em 2016 para o Teatro Temporário ao Ar Livre no Campus da Praia Vermelha da Universidade Federal do Estado do Rio de Janeiro (Figura 1).

Decidiu-se que a proposta a ser submetida à PQ19 para ser exibida na seção de espaços para performance seria o trabalho colaborativo realizado pelos pesquisadores do referido Laboratório, que consistiria em recuperar os projetos de arquitetura e cenografia assim como os vídeos do site-specific ou Temporary Open-Air Theatre criado em 2016, remontar um vídeo-síntese de 5 minutos e enviar para os curadores da seção Our Theatre of the World.

\section{Figura 1 - Entrada do Campus da Praia Vermelha da Universidade Federal do Estado do Rio de Ja- neiro - Unirio.}

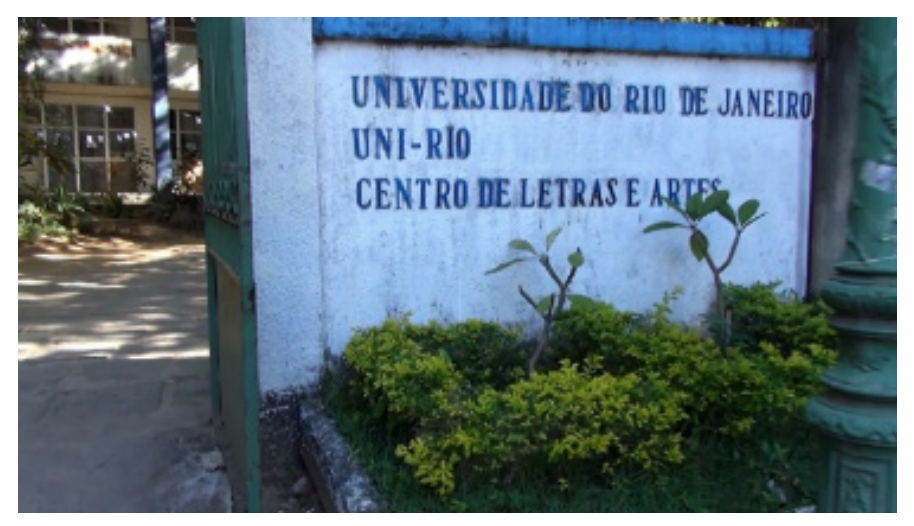

Fonte: Foto da autora, 2018. 
A proposta e a execução do projeto foram formuladas na ocasião da comemoração dos 400 anos da morte de Shakespeare, e, após inúmeras reuniões, pedidos de licenças acadêmicas e consultas técnicas, optou-se por construir um espaço temporário no local de uma antiga ruína, uma clareira entre as árvores na parte mais elevada à direita do Jardim Mário de Andrade do Centro de Letras e Artes.

Este jardim é repleto de significados, visto que o Centro de Letras e Artes ocupa algumas edificações históricas - como a antiga estação de 1908, adaptada como a Sala Glauce Rocha - e, provavelmente, a área selecionada havia abrigado pequenas construções, apresentando diversos patamares ascendentes que culminam no sopé do Morro da Babilônia (Figura 2). Os remanescentes dos pisos de ladrilhos hidráulicos existentes no local indicavam a existência de antigas construções.

\section{Figura 2 - Localização do Teatro Temporário ao Ar} Livre no campus Praia Vermelha.

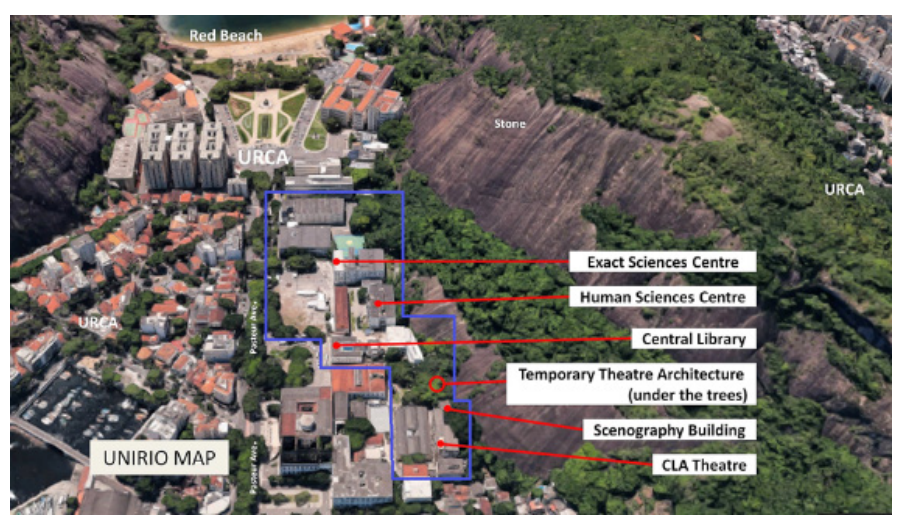

Fonte: Marcações sobre o Google Earth, 2018.

\section{O "espaço encontrado"}

O "espaço encontrado" pode ser considerado um "local praticado" na concepção de Michel de Certeau (1994), de intensa utilização pelos alunos das áreas de teatro, música, letras e humanidades em geral, cujos prédios se localizam no Campus da Praia Vermelha. A qualquer hora do dia, os jardins que homenageiam Mario de Andrade - o grande autor do Modernismo Brasileiro - ficam repletos de alunos trocando ideias, lanchando, tocando instrumentos musicais entre outras atividades. Mas nunca fora utilizado como um teatro efêmero até a apresentação do site-specific objeto deste artigo.

$O$ referido jardim, em platôs ascendentes, situa-se na encosta do Morro da Babilônia, e foi - local escolhido para a construção do espaço teatral efêmero, em comum acordo entre os arquitetos e cenógrafos do Laboratório, que utilizaram como "found space" uma clareira no canto superior direito do jardim, espaço com luxuriante vegetação tropical e intensamente arborizado.

Localizado ao longo da alameda que conduz os transeuntes aos prédios das Artes Cênicas, da Música e do Teatro Paschoal Carlos Magno - carinhosamente denominado "Palcão" pelos estudantes, o Jardim Mario de Andrade ofereceu um lócus perfeito para o projeto, que teve como espectadores alunos, professores e funcionários do Centro de Letras e Artes (Figura 3).

Figura 3 - Jardim Mário de Andrade, em platôs ascendentes no sopé do Morro da Babilônia, 2018.

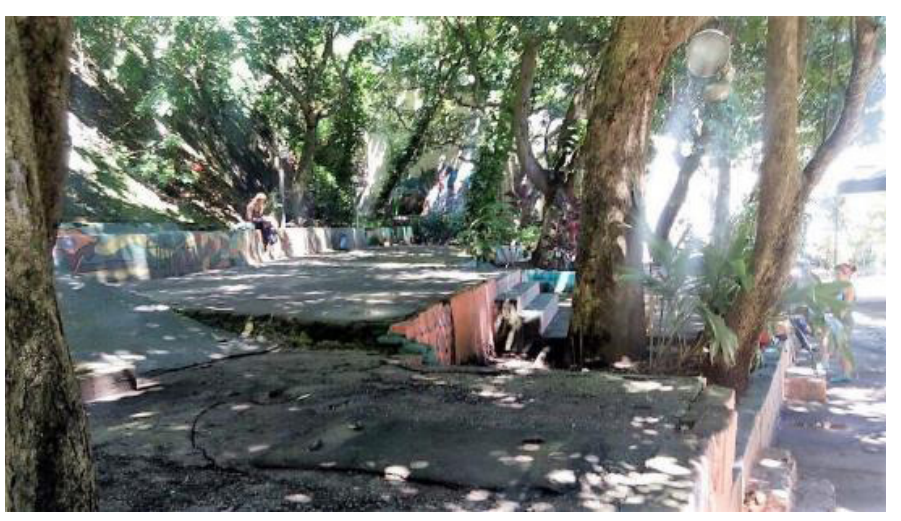

Fonte: Foto de Milena Fernandes, 2018.

Em síntese, esta opção de "found space" significou que o palco-plataforma retornou ao espaço aberto, ao espaço da praça do mercado - da verdadeira esfera pública e que o evento, apresentado num local marcado culturalmente e politicamente pelo coletivo de docentes e discentes da Unirio, uniu performance e comunidade. 


\section{O projeto arquitetônico e cenográfico}

Seguindo os croquis preliminares os arquitetos realizaram os levantamentos do terreno e desenvolveram o projeto para um palco descoberto em diferentes níveis e desenharam a proposta para construir uma estrutura efêmera basicamente composta por um deck encimado por trainéis articulados. Os arquitetos projetaram uma plataforma de concreto para nivelar o antigo piso em ruínas, desenharam praticáveis com três diferentes níveis e uma escada vazada (Figuras 4 e 5). Sobre a plataforma, foram instalados três trainéis com estrutura metálica articulada tipo biombo com 1,25m de largura $\times 2,40 \mathrm{~m}$ de altura (Figura 6). O piso foi forrado de tabuado de pinho e recoberto com folhas de algodoeiro e de mangueira, integrando-se perfeitamente à paisagem local.

Figura 4 - Teatro Temporário ao Ar Livre na Unirio - Planta de implantação.

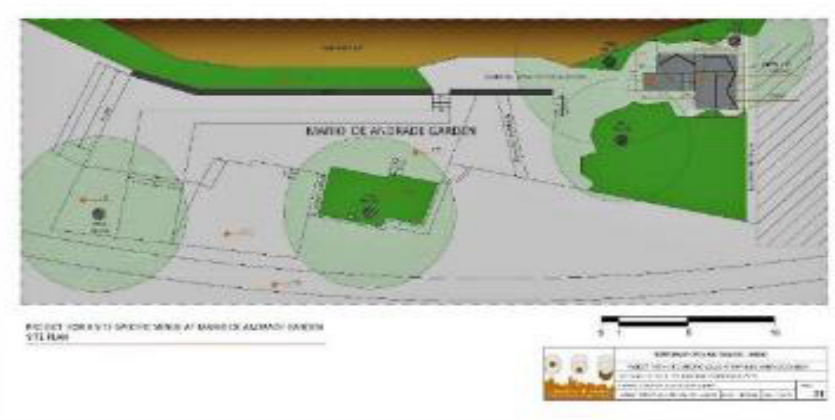

Fonte: Desenho de Sara Fagundes e Francisco Leocádio, 2016.
Figura 5 - Teatro Temporário ao Ar Livre na Unirio - Seção horizontal da proposta.

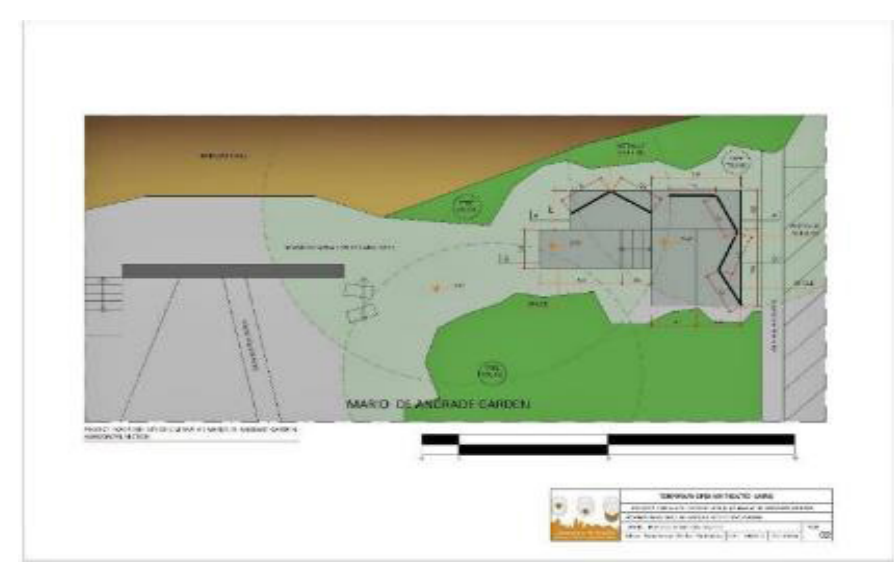

Fonte: Desenho de Sara Fagundes e Francisco Leocádio, 2016.

Figura 6 - Teatro Temporário ao Ar Livre na Unirio - Seções verticais da proposta.

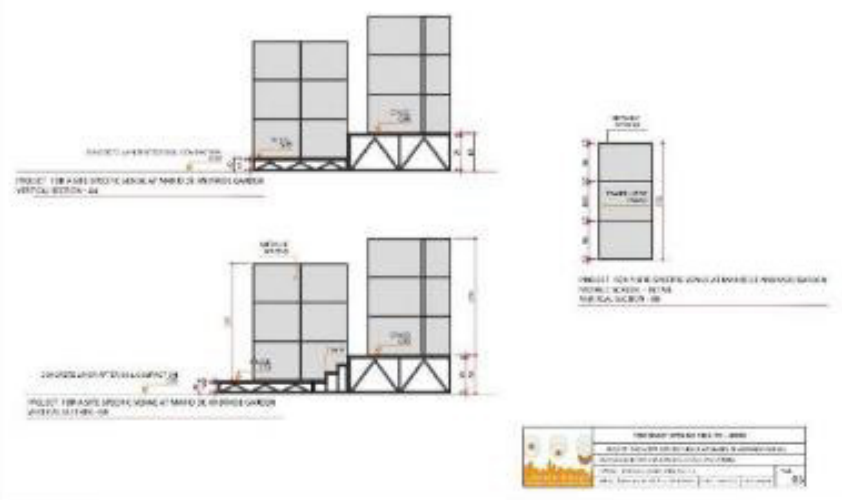

Fonte: Desenho de Sara Fagundes e Francisco Leocádio, 2016.

À princípio, os cenógrafos haviam sugerido a utilização de autênticas redes de pescar para a forração dos trainéis metálicos articulados, além de uma ampulheta e algumas cestas bem rudimentares que seriam colocadas nos praticáveis. No fim, ficou decidido preencher os vazios dos trainéis articulados com tule de nylon branco, que mudariam de cor e de textura de acordo com o projeto de iluminação (Figuras 7 e 8). 
Paralelamente, para representar a biblioteca de Próspero, colocou-se um conjunto de livros sobre a plataforma, enquanto as toras para a lenha trazidas por Caliban foram sintetizadas por alguns galhos obtidos no próprio jardim. Enfim, as metáforas que envolveriam os espectadores obedeceram em certa medida, as práticas elisabetanas, sendo os signos transmitidos por objetos sugestivos. Como afirma Kathleen Irwin, em propostas site-specific, o cenógrafo é "uma espécie de dramaturgo visual" e sua prática "envolve estética, teoria e considerações práticas" (IRWIN, 2007, p. 41).

Figura 7 - Planta humanizada do piso.

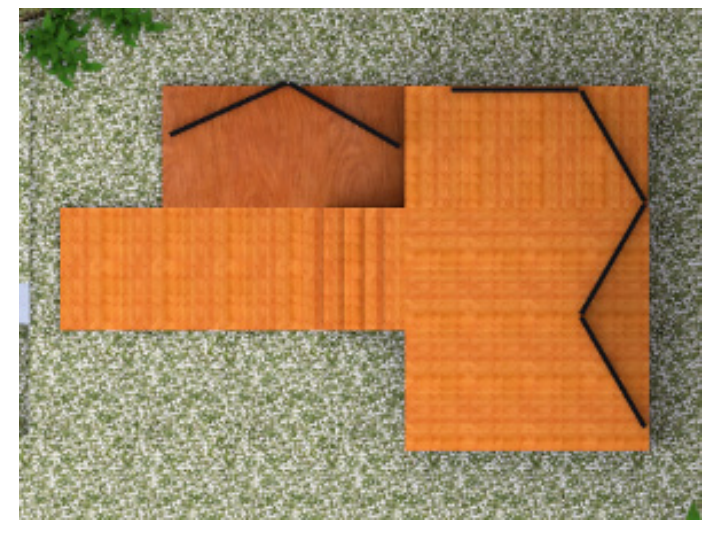

Figura 8 - Perspectiva humanizada.

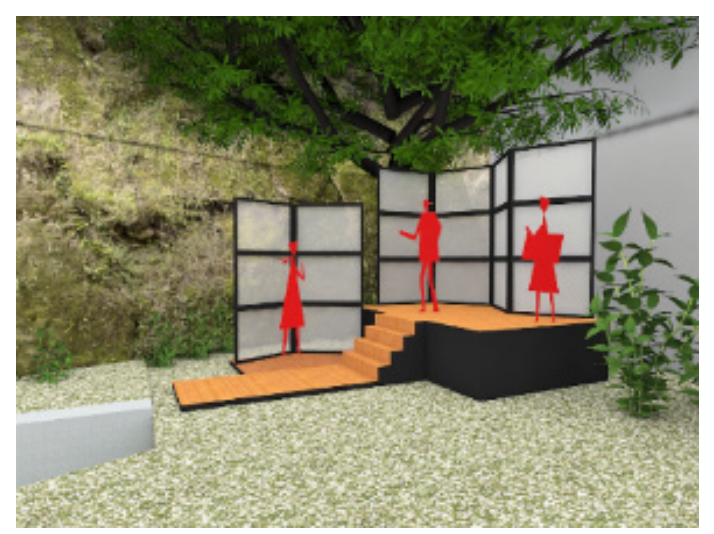

Fonte: Desenho de Sara Fagundes, 2016.

A Universidade arcou com os serviços de adequação dos praticáveis e a arquiteta coordenadora do projeto contribuiu para a aquisição de alguns itens não disponibilizados pela universidade. Os praticáveis de aço foram construídos a partir das diferentes alturas requeridas pelo terreno irregular. Foi previsto que a estrutura efêmera poderia ser também utilizada para outras performances e shows musicais enquanto estivesse disponível, durante os três meses subsequentes à performance.

\section{A iluminação cênica e o som}

No que tange à iluminação, foram utilizados o prédio da Cenografia e a Sala Glauce Rocha (Sala Cinza) como apoio técnico para som e iluminação cênica, que ficou a cargo de uma das cenógrafas, também professora de iluminação.

Inicialmente, concebeu-se uma proposta de instalação de torres verticais box truss para dar suporte à iluminação cênica, bem como a instalação de uma cabine de apoio para operação de luz e som durante os espetáculos. Tal hipótese foi abandonada porque ficou muito além do orçamento do projeto.

A proposta definitiva foi criada com refletores instalados nas duas frondosas árvores existentes no jardim que determinaram a largura máxima possível para o deck do palco. A cabine de som foi improvisada sobre um dos patamares, próxima aos espectadores que se reuniram em todos os níveis do jardim para assistir e participar do espetáculo. Tal como proposto por Adolphe Appia (1990 [1921]) no início do século $X X$, o projeto de iluminação enfatizou as qualidades do espaço e da vegetação tropical nativa, esculpindo o palco com a luz (Figura 9). 
Figura 9 - Teatro Temporário ao Ar Livre na Unirio no teste de iluminação cênica no dia da performance.

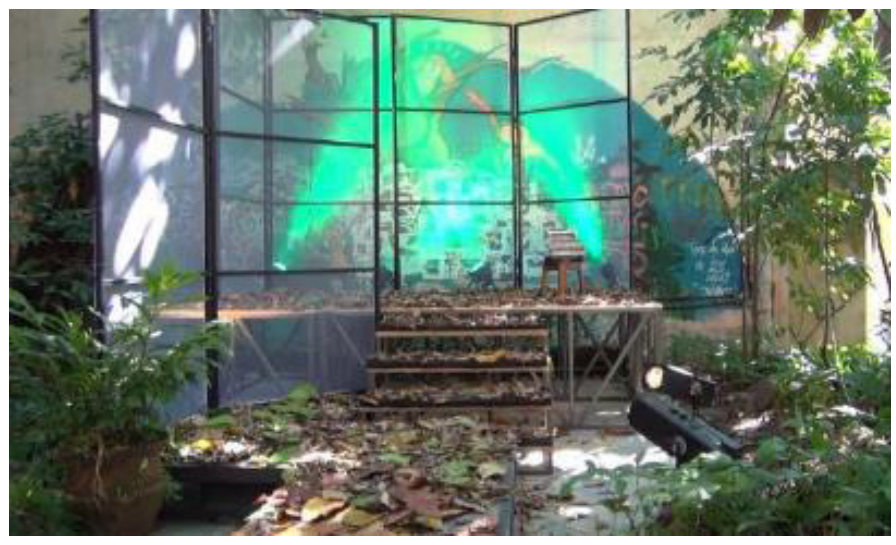

Fonte: Foto da autora, 2016.

\section{O figurino}

Numa primeira proposta, o figurino apresentaria algumas silhuetas em fita de led, porém ao final, decidiu-se que o site-specific seria apresentado à luz natural ao entardecer, conforme estabelecido pela equipe que também acordou que os performers utilizariam indumentárias desenhadas por duas figurinistas-pesquisadoras do Laboratório e que a personagem do espírito, Ariel, seria apenas um figurino etéreo acionado por sistema do Teatro de Bonecos, com a voz de um dos atores.

Seguindo o conceito de Aronson (2005, p. 18) para o qual o design pós-moderno frequentemente utiliza referências do passado e imitações estilísticas que funcionam como um código semiótico, uma das figurinistas criou um manto para Próspero recoberto de imagens de livros renascentistas, aludindo ao seu profundo amor pelo conhecimento erudito, enquanto Caliban, quase nu, cobria apenas algumas partes do corpo com penas de aves. (Figura 10).
Figura 10 - Teatro Temporário ao Ar Livre na Unirio. Aspectos do figurino.

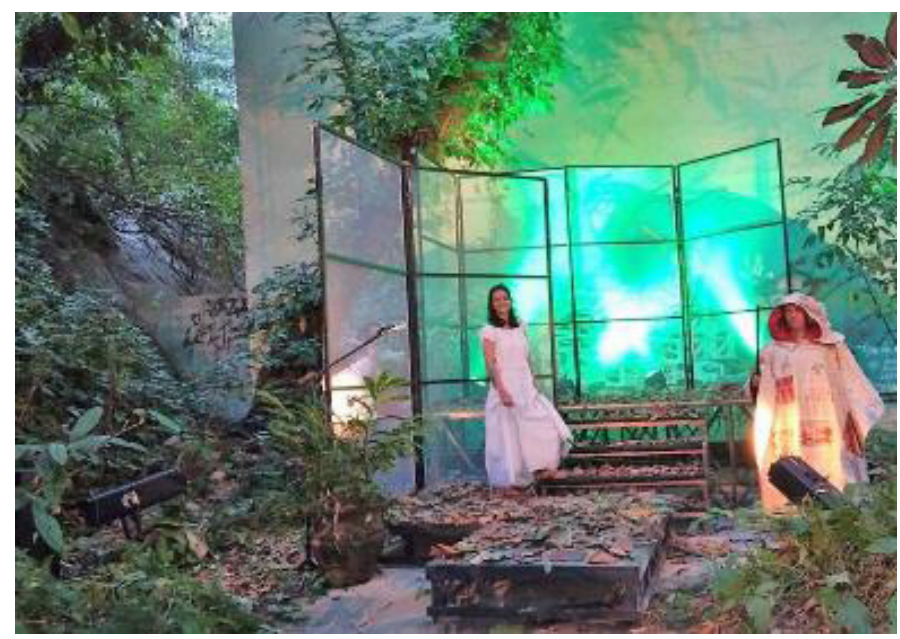

Fonte: Foto da autora, 2016.

A atuação cênica

O site-specific de 40 minutos envolveu alunos e profissionais do Laboratório, além de um diretor convidado que atuou também como performer de diversos personagens, e foram apresentados fragmentos da peça A Tempestade para homenagear Shakespeare, nos 400 anos de sua morte. Os performers circulavam entre a plateia em pé, acentuando as descontinuidades com breves interrupções. As atuações foram brilhantes e provocaram grande impacto.

Todavia, cabe lembrar que a escolha da peça obedeceu a reflexões preliminares que estão aqui sintetizadas.

\section{Reflexões que antecederam à montagem:} a espetacularidade em Shakespeare

É fato que o teatro inglês que se estuda hoje não surgiu repentinamente no período elisabetano. Quando Shakespeare começou a trabalhar como dramaturgo, a Inglaterra já apresentava há mais de dois séculos uma tradição contínua de atuação tanto religiosa quanto profana. As praças, os mercados e as esquinas das ruas eram locais em que ocorriam as apresentações teatrais no período medieval. Cabe 
ressaltar que no período elisabetano, as peças dramáticas eram encenadas em tipos diferentes de palco (i) no teatro privado, ocorria nos salões na corte e nas residências nobres e, (ii) no teatro público, nos pátios das estalagens e nos amphitheatres, inspirados no espaço das arenas de lutas de ursos (GURR, 1992).

Identificou-se que, em geral, nas peças de Shakespeare, pode-se aplicar a teoria certeaudiana de que seus contos apresentam análises de acurada percepção das combinações de táticas fundamentadas em unidades elementares que não são nem significações nem seres, mas ações relativas a situações conceituais daquela sociedade (LIMA, 2013). Esta leitura perspicaz permitiria reconhecer nos textos dramatúrgicos os discursos estratégicos do povo (CERTEAU, 1994). O "espetacular" era antes de tudo uma forma de entretenimento, e, como tal, deveria atender às expectativas do público, fosse ele popular ou aristocrático.

Segundo Pascale Drouet, no contexto aristocrático, o espetacular em geral está ligado às questões políticas e ao aparato hegemônico; a economia do espetacular não pode ser desassociada da ideologia dominante (DROUET, 2009, p. IX). No contexto popular, entende-se que haja no homem este desejo de maravilhar-se, mas também de estranhamento diante do espetacular. A Tempestade de Shakespeare demonstra a maturidade do autor, que projeta nas ações de Próspero os valores sociais e morais da época. O projeto de vingança de Próspero leva-o a mergulhar nos estudos bibliográficos de sua época, e o faz apaixonar-se pelos livros de magia. Exilado numa ilha desconhecida com sua filha Miranda, Próspero vence a bruxa Sycorax e adota o seu filho, Caliban, mistura de monstro e homem.

Apesar dos esforços para vencer os elementos da ilha e criar sua filha e Caliban, Próspero não consegue muito sucesso. A peça inicia-se justamente no momento que ele coloca seu plano de vingança em curso. Com a ajuda de Ariel, espírito do bem, provoca uma perigosa tempestade sobre o navio no qual estavam Antônio, Sebastião e Alonso, que o haviam traído. Os náufragos conseguem atingir a ilha e passam a ser encantados até que Próspero revelasse as razões da situação. Após conversar longamente com Ariel sobre as possibilidades das falhas humanas e de como o amor poderia melhorar a vida para homens fracos, o protagonista traído perdoa os ofensores, confirmando a máxima de que "tudo está bem quando termina bem".

O que se verifica em A Tempestade é a natureza híbrida de Caliban, as metamorfoses fantásticas de Ariel, a mágica introdução de Próspero repleta de efeitos espetaculares. Na cena final, a espetacularidade se acentua: Ariel entra invisível e uma música estranha envolve a cena e, em meio a trovões e raios, um grande estrondo persegue as ninfas que dançam. A peça denota uma encenação repleta de elementos fantásticos e oníricos, quase surrealistas, que comprovam o viés maneirista de Shakespeare.

Entre as análises recentemente publicadas de A Tempestade destaca-se a de John Demarey, que desenvolve um interesse pela tradição das Masques, muito comuns nos teatros de Corte. Pelo seu argumento, esta peça, exibida em première no Whitehall, absorveu a estrutura das Mascarades, conforme consta do texto dramatúrgico publicado no First Folio. Para este autor, qualquer análise da peça estaria incompleta sem se levar em conta o contexto de sua produção inicial, ou seja, em um teatro da corte (DEMAREY, 1998, p.174). O estudioso acredita que a peça seria um trabalho já de transição entre o drama encenado e as futuras adaptações desta obra como a de Sir Willian Davenant, que encenou A Tempestade em 1670 já nos moldes do drama espetacular do período da Restauração. O historiador Roger Chartier também se refere ao fato de a companhia de Sir William Davenant ter recebido o monopólio de Hamlet e de oito peças de Shakespeare que ele adaptou para montagens que realizou em Lincoln Inn's Field, e em 1671 no seu novo teatro em Dorset Gardens (CHARTIER, 2002, p. 84).

Enfim, A Tempestade constitui um apanhado de mágicas, rituais e temas contraditórios que possibilitam um espetáculo contínuo no palco, porém que não encerra uma 
verdadeira história fechada, portanto, perfeita para ser apresentada como um espetáculo site-specific ${ }^{2}$.

\section{Por quê um site-specific}

Como o site-specific estava homenageando Shakespeare, a performance escolhida remetia a um texto que, apesar de aberto e fragmentado, é um texto dramatúrgico, contrariamente às propostas pós-dramáticas. Para a pesquisadora Katleen Irwin, em que pese a cenografia tradicional em espaços especificamente construídos para o teatro ser sempre centrada no texto, ela também fica confortável nas performances que acontecem no "found space" nas quais a materialidade do local é igual ou mais privilegiada do que o texto. Esta autora entende que as estratégias de cenografia empregadas em circunstâncias de site-specific, sugerem uma forma híbrida de apresentação, que recebem seu impulso do mundo material. Paralelamente, a autora argumenta que o impulso para considerar lugares particulares em termos performativos surge em uma elaboração do conceito de "heterotopia" de Michel Foucault, uma noção que reconhece certos lugares como superposições complexas e em camadas de todos os outros locais dentro de um paradigma sociocultural (IRWIN, 2007, p. 50).

Nesse sentido, a equipe entendeu que poderia encenar apenas alguns fragmentos visto que a peça ocorre em um contexto que, embora dramático, abrange uma variedade de circunstâncias físicas que não são notoriamente teatrais e que permitiriam uma complexa troca entre a performance, o espectador e o local repleto de significados, tal como proposto por Irwin (2007, p. 39).

Apesar de alguns autores defenderem que a primeira montagem de $A$ Tempestade foi no Blackfriars, segundo Kermode, a primeira performance

$2 \mathrm{Na}$ verdade, a dramaturgia e as didascálias remetem às Masques, escritas por Ben Jonson, porém valorizadas pelos magníficos cenários de Inigo Jones, que trouxe da Itália uma nova concepção de cenografia com base na perspectiva, procedimento gráfico redescoberto por Brunelleschi no Quattrocento (LIMA, 2013). registrada ocorreu em 1 de novembro de 1611 para a corte de James I no Banqueting House do palácio Whitehall (KERMODE apud KEISER, 2014).

No que tange ao local, tão diferente do palco do Whitehall no qual $A$ Tempestade foi encenada pela primeira vez, remete-se à afirmativa de Miwon Kwon, quando afirma que "dessa maneira, o "local" da arte distancia-se do espaço literal da arte; e a condição física de localização específica retrocede como elemento principal na concepção de um local." (KWON, 1997, p. 91)33.

Em seu livro Theatre Archeology (2001), reconhecendo as diferentes camadas acumuladas nos espaços ao longo do tempo e encorajando a criação de performances fora do edifício teatral, Mike Pearson e Michael Shanks sugerem novos insights teóricos relacionando locais que melhor interagem com arquitetura, teatro e cenografia, referindo-se com acuidade ao conceito de site-specific quando afirmam que:

As performances site-specific são concebidas, montadas e condicionadas pelos detaIhes dos espaços encontrados, pelas situações sociais existentes e pelas localizações, usados ou em desuso [...]. Elas se apoiam, para suas concepções e interpretações, na complexa coexistência, sobreposição e interpenetração de várias narrativas e arquiteturas, históricas e contemporâneas, de duas ordens básicas: (i) aquela que é preexistente no local, suas características e acessórios e (ii) aquela que é trazida ao lugar, como a performance e sua cenografia; (i) daquilo que preexiste ao trabalho e

3 In these ways, the 'site' of art evolves away from its coincidence with the literal space of art; and the physical condition of specific location recedes as the primary element in the conception of a site (KWON, 1997, p. 91). 
(ii) aquilo que é do trabalho; (i) do passado e (ii) do presente. (PEARSON; SHANKS, 2001, p. 23 , tradução livre da autora $)^{4}$

O Teatro Temporário ao Ar livre na Unirio, ao propor um site-specific sobre vestígios de uma ocupação que data da Exposição Universal de 1908, sediada na Praia Vermelha, porém integrando a Mata Tropical Atlântica que cobre parte do Morro da Babilônia para realizar uma performance com base em A Tempestade de Shakespeare, enfatiza o aspecto da conquista de novas colônias, tal como alude a peça. Pode-se afirmar que a performance recontextualiza o "found space" visto que trata da ocupação mais recente de um local cujos antigos vestígios e histórias materiais ainda são aparentes e "o local não é apenas um pano de fundo interessante e desinteressado. [...] Os múltiplos significados e leituras de performance e site se misturam, alterando-se e se comprometendo um com o outro", tal como apontam Pearson e Shanks (2001, p. 23).

\section{Algumas considerações}

A equipe que participou da Exposição Our Theatre of the World da PQ19 entende que este Teatro Temporário ao Ar Livre na Unirio foi realmente um site-specific, visto que foi um espaço concebido em um lugar do jardim com forte significação histórica, integrante do entorno da antiga Estação de Bondes inaugurada em 1908, atualmente o Teatro Glauce Rocha, tombado pelo INEPAC. Além do valor histórico, o Jardim Mário de Andrade, no qual foi feita a instalação

4 Site-specific performances are conceived for, mounted within and conditioned by the particulars of found spaces, existing social situations or locations, both used and disused [...]. They rely, for their conception and their interpretation, upon the complex coexistence, superimposition and interpenetration of a number of narratives and architectures, historical and contemporary, of two basic orders: that which is of the site, its fixtures and fittings, and that which is brought to the site, the performance and its scenography: of that which preexists the work and that which is of the work: of the past and of the present (PEARSON; SHANKS, 2001, p. 23). artística, tem forte significado sociológico para todo o alunado de Artes e de Humanidades que frequenta diariamente o Campus da Unirio da Praia Vermelha.

Portanto, quando se encenaram alguns fragmentos de A Tempestade ${ }^{5}$ de Shakespeare naquele bairro carioca à beira-mar, de complexa interpenetração de narrativas, arquiteturas e tempos históricos tem-se consciência de se ter trazido para o "espaço encontrado" uma experiência de arquitetura, de cenografia e de performance contemporâneas interligando diferentes temporalidades: (i) o passado da encenação shakespeariana, (ii) o passado bucólico do próprio espaço ocupado desde o início do século $X X$ e (iii) a performance do século XXI que provocou no público diferentes emoções.

O resultado da obra de criação cênica, aliando arquitetura, desenho da cena, iluminação, figurino e atuação assumiu sua completude durante a performance. O espetáculo despertou a consciência do público para a mensagem do site-specific, como atestam as entrevistas com a plateia que interagiu com os performers, alegando que a recepção foi impactante e inovadora como consta no vídeo de 40 minutos de 2016 . Ficou claro que aquele espaço impregnado de historicidade, apesar de ser hoje uma paisagem bucólica, teve acrescida à memória aquela performance, atestando que o projeto incorporou os vários passados e o presente.

O fato de a equipe do Temporary Open-Air Theatre ter sido finalista da Exposição denota os esforços da Quadrienal de Praga 2019 para celebrar o trabalho dos arquitetos, designers e artistas no

5 Ficha técnica: O projeto/A Performance (2016). Arquitetos: Evelyn F.W. Lima, Francisco Leocádio, Sara M. Fagundes; Performance Designers: Joana Lavallé, Carolina Lyra, Debora Estruc; Costume designers: Regilan Pereira e Carla Costa ; lighting designer: Ana Paula Guedes Diretor de Cena: Raphael Janeiro; Performers: Próspero: Edson Santiago, Miranda: Natalia Gadiolli, Caliban: Raphael Janeiro, Fernando: Raphael Janeiro, Voz de Ariel: Raphael Janeiro. Vídeo de 40 minutos (filmagem e decupagem): Evelyn F.W. Lima e Milena Fernandes; Vídeo de 5 minutos para o concurso da PQ19 (2018). Direção: Evelyn F.W. Lima e Milena Fernandes. Roteiro: Evelyn F.W. Lima; Edição: Milena Fernandes; Legendas em Inglês: Evelyn F.W. Lima. 
sentido de educar e formar plateias, relevantes características da performance ao vivo no século XXI.

Finalmente, considera-se que tanto o processo de projeto e construção do teatro efêmero, quanto a seleção e o estudo do teatro elisabetano, quanto o instigante processo de realização do vídeo de apenas 5 minutos que pudesse elucidar o júri a partir do vídeo já existente, representaram um desafiante procedimento para suplantar a personalidade individual pela visão de grupo.

O vídeo do projeto do Teatro Temporário ao Ar Livre ficou em exibição durante o período de 06 a 16 de junho na Prague Quadrennial 2019 e recebeu muitos comentários positivos do público que esteve presente naquele prestigioso evento. TODD

\section{Referências}

APPIA, Adolphe. Oeuvres complètes. Edição elaborada e comentada por Marie L. Bablet-Hahn, Societé suisse du théâtre/ l'Âge d'Homme, Vol. II, 1990.

ARONSON, Arnold. Looking into the Abyss. Essays on Scenography. USA: University of Michigan Press, 2005.

BAUGH, Christopher. Theatre, Performance and Technology: The Development of Scenography in the Twentieth Century. Basingstoke and New York: Palgrave Macmillan, 2013.

CERTEAU, Michel de. A invenção do cotidiano: artes de fazer. Petrópolis: Vozes, 1994.

CHARTIER, Roger. Do palco à página. Publicar teatro e ler romances na época moderna. Rio de Janeiro: Casa da Palavra, 2002.

DEMAREY, John G. Shakespeare and the Spectacles of Strangeness: The Tempest and the Transformation of Renaissance Theatrical Forms. Pittsburgh: Duquesne University Press, 1998.
DROUET, Pascale. Introduction. In: The Spectacular In and Around Shakespeare. Cambridge Scholars, 2009. GURR, Andrew. The Shakespearean Stage 1574-1642. $3^{\text {a }}$ ed. Cambridge, Cambridge University Press, 1992.

IRWIN, Kathleen. The Ambit of Performativity. How Site Makes Meaning in Site-Specific Performance. Helsinki: University of Arts and Design Helsinki, 2007.

KEISER, Melissa. Pre-twentieth Century Productions of The Tempest, 2014. Disponível em: http:// www2.cedarcrest.edu/academic/eng/ffletcher/tempest/papers/MKeiser.htm. Acesso em: 12 fev. 2020.

KWON, Miwon. One Place after Another: October, v.80., p. 85-110. Spring, 1997. Disponível em :http://links.jstor.org/sici?sici=0162-2870\%28199721\%2980\%3C85\%3AOPAANO\%3E2.0.CO\%3B2-I. Acesso em: 12 fev. 2020.

LIMA, Evelyn Furquim Werneck. Notas sobre cenografia. Dispositivos cênicos espetaculares em espetáculos do século XVII e na contemporaneidade. Urdimento n. 20, set., p. 98-104. 2013.

PEARSON, Mike; SHANKS, Michael. Theatre Archeology. Londres: Routledge, 2001.

TODD, Andrew ( curator). Call for Applications: Performance Space Architecture Exhibition our Theatre of the World. PQ19. Disponível em http:// www.pq.cz/wp-content/uploads/2018/03/OurTheatre-of-the-World-Architecture-Call-Deadline-Extended.pdf. Acesso em 11 maio 2020.

Aprovado: $12 / 03 / 2020$

Recebido: 31/05/2020 